\title{
Fe atoms anchored on defective nitrogen doped hollow carbon spheres as efficient electrocatalysts for oxygen reduction reaction
}

\author{
Panpan $\mathrm{Su}^{1,2, \S}$, Wenjuan Huang ${ }^{1,2, \S}$, Jiangwei Zhang ${ }^{2,3, \S}$, Utsab Guharoy ${ }^{2,4}$, Qinggang Du ${ }^{1,2}$, Qiao Sun ${ }^{4}$, Qike Jiang ${ }^{3,5}$, \\ Yi Cheng ${ }^{6,7}$, Jie Yang ${ }^{1}(\varangle)$, Xiaoli Zhang ${ }^{8}$, Yongsheng Liu ${ }^{1}$, San Ping Jiang ${ }^{7}$, and Jian Liu $^{2,7,9}(\varangle)$ \\ ${ }^{1}$ College of Mathematics and Physics, Shanghai University of Electric Power, Shanghai 200090, China \\ ${ }^{2}$ State Key Laboratory of Catalysis, Dalian Institute of Chemical Physics, Chinese Academy of Sciences, Dalian 116023, China \\ ${ }^{3}$ Dalian National Laboratory for Clean Energy, Dalian Institute of Chemical Physics, Chinese Academy of Sciences, Dalian 116023, China \\ ${ }^{4}$ State Key Laboratory of Radiation Medicine and Protection, Collaborative Innovation Center of Radiation Medicine of Jiangsu Higher \\ Education Institutions, School for Radiological and Interdisciplinary Sciences, Soochow University, Suzhou 215123, China \\ ${ }^{5}$ Division of Energy Research Resources, Dalian Institute of Chemical Physics, Chinese Academy of Sciences, Dalian 116023, China \\ ${ }^{6}$ Department of Environmental Engineering, School of Metallurgy and Environment, Central South University, Changsha 410083, China \\ ${ }^{7}$ WA School of Mines: Minerals, Energy and Chemical Engineering, Curtin University, Perth, WA 6102, Australia \\ ${ }^{8}$ State Centre for International Cooperation on Designer Low-Carbon \& Environmental Materials, School of Materials Science and Engineering, \\ Zhengzhou University, Zhengzhou 450001, China \\ ${ }^{9}$ DICP-Surrey Joint Centre for Future Materials, Department of Chemical and Process Engineering, University of Surrey, Guildford, Surrey, \\ $U K$ \\ ${ }^{\S}$ Panpan Su, Wenjuan Huang, and Jiangwei Zhang contributed equally to this work.
}

(C) The Author(s) 2020

Received: 24 June 2020 / Revised: 22 September 2020 / Accepted: 30 September 2020

\begin{abstract}
Defective electrocatalysts, especially for intrinsic defective carbon, have aroused a wide concern owing to high spin and charge densities. However, the designated nitrogen species favorable for creating defects by the removal of nitrogen, and the influence of defects for the coordination structure of active site and oxygen reduction reaction (ORR) activity have not been elucidated. Herein, we designed and synthesized a pair of electrocatalysts, denoted as Fe-N/C and Fe-ND/C for coordination sites of atomic iron-nitrogen and iron-nitrogen/defect configuration embedded in hollow carbon spheres, respectively, through direct pyrolysis of their corresponding hollow carbon spheres adsorbed with $\mathrm{Fe}(\mathrm{acac})_{3}$. The nitrogen defects were fabricated via the evaporation of pyrrolic- $\mathrm{N}$ on nitrogen doped hollow carbon spheres. Results of comparative experiments between Fe-N/C and Fe-ND/C reveal that Fe-ND/C shows superior ORR activity with an onset potential of $30 \mathrm{mV}$ higher than that of Fe-N/C. Fe-ND sites are more favorable for the enhancement of ORR activity. Density functional theory (DFT) calculation demonstrates that Fe-ND/C with proposed coordination structure of $\mathrm{FeN}_{4-x}(0<x<4)$ anchored by $\mathrm{OH}$ as axial ligand during ORR, weakens the strong binding of $\mathrm{OH}^{*}$ intermediate and promotes the desorption of $\mathrm{OH}^{*}$ as rate-determining step for ORR in alkaline electrolyte. Thus, Fe-ND/C electrocatalysts present much better ORR activity compared with that of $\mathrm{Fe}-\mathrm{N} / \mathrm{C}$ with proposed coordination structure of $\mathrm{FeN}_{4}$.
\end{abstract}

\section{KEYWORDS}

atomic iron, nitrogen defect, coordination environment, hollow carbon spheres, oxygen reduction reaction

\section{Introduction}

Energy crisis and environmental pollution demands clean energy storage and conversion technologies [1]. Polymer electrolyte membrane fuel cells and metal-air batteries are new-generation energy conversion devices with high energy density which have drawn enormous attention in recent years due to its high efficiency and zero emission [2]. The oxygen reduction reaction (ORR), as a key cathodic reaction, directly affects the output energy capacity of these devices. However, the sluggish kinetics of the multiple proton-couple electron transfer procedures limits the whole efficiency [3]. Although noble-metal catalysts (especially $\mathrm{Pt} / \mathrm{C}$ catalyst) have demonstrated prominent ORR activity, their high-cost and limited resources have stimulated tremendous efforts to explore precious-metal-free ORR catalysts aiming to substitute noble-metal based catalysts.

During the last few decades, tremendous efforts have been devoted to exploring the alternatives to replace noble-metalbased catalysts from nanoscale engineering to atomic design [4-9]. Among them, atomic transition metal-nitrogen co-doped carbon materials (M-N/C) have aroused widespread attention [10-13]. Latest demonstrations reveal that single metal atoms coordinated with nitrogen forming $\mathrm{M}-\mathrm{N}_{x}$ sites serve as the active centers for ORR, particularly $\mathrm{Fe}$ and Co-based catalysts $[12,13]$. Strategies to improve the performance of single-atom catalysts are widely investigated such as increasing the density of active sites, enhancing the intrinsic activity of catalyst by the construction of bi-metal or tri-metal active sites or regulation of coordination environment of active sites [6, 14-17]. Introduction of intrinsic defects is identified as effective method to tune the 
coordination structure of single active site [18-21]. Recently, Yao and co-workers demonstrate that defective graphene or carbon capsules with amounts of structural defects provide unique coordination environment for metallic species that exhibits more excellent electrocatalytic activity than that of M-N/C catalysts due to the high spin and charge densities [22-26]. In addition, the defect on Co- $\mathrm{N}$ sites co-doped carbon is essential for the formation of Co- $\mathrm{N}_{4-x}$ besides of Co- $\mathrm{N}_{4}$ [27]. Among them, treatment at elevated temperatures is a relatively facile method for nitrogen removal to form vacancy defects. However, the question about which nitrogen species mainly contributed to the defects and the effect of defect for coordination structure of atomic Fe is rarely reported. Thus, it is important to identify the defective sites generated by nitrogen species loss and optimize the coordination environment of atomic Fe to design promising ORR catalysts.

With the aim to disclose the defect sites generated by the evaporation of the nitrogen species, high specific surface area hollow carbon spheres combining the atomic iron active sites coordinated with nitrogen/defects were synthesized and their ORR activities were evaluated. In alkaline electrolyte, ironnitrogen/defect co-doped hollow carbon spheres (Fe-ND/C) show the higher ORR activity than that of the atomic ironnitrogen doped hollow carbon spheres (Fe-N/C). As the increase of the defect contents on Fe-ND/C catalysts, the pyrrolic-N evaporation generates new active sites for ORR activities. It means that the defect sites are produced via the evaporation of pyrrolic-N. The enhanced ORR activities of Fe-ND/C verify that $\mathrm{Fe}-\mathrm{ND}$ as active center are more favorable for ORR than $\mathrm{Fe}-\mathrm{N}$.

\section{Experimental}

\subsection{Materials}

Tetraethoxysilane (TEOS, 98\%), ammonia solution (25\%-28\%), formaldehyde solution (37 wt.\%), N,N-dimethylformamide (DMF) and ethanol were purchased from Sinopharm Chemical Reagent Company. Melamine and Iron(III) 2,4-pentanedionate $\left(\mathrm{Fe}(\mathrm{acac})_{3}\right)_{\text {were }}$ purchased from Aladdin. Pluronic F127 was purchased from sigma. Resorcinol was purchased from Energy chemical. Hydrochloric acid ( $\mathrm{HCl})$ and hydrofluoric acid (HF) were purchased from Kemiou Chemical Reagent Company. All of the reagents were of analytical grade and used as received without further purification.

\subsection{Preparation of $\mathrm{SiO}_{2} @ \mathrm{MRF}$}

In a typical experiment, ammonia aqueous solution $\left(\mathrm{NH}_{4} \mathrm{OH}\right.$, $2.5 \mathrm{~mL}$ ), absolute ethanol (EtOH, $60 \mathrm{~mL}$ ) and deionized water $\left(\mathrm{H}_{2} \mathrm{O}, 20 \mathrm{~mL}\right)$ were mixed and stirred at the rate of $370 \mathrm{rpm}$ for $30 \mathrm{~min}$ at $30^{\circ} \mathrm{C}$. TEOS $(2.8 \mathrm{~mL})$ was subsequently added into the mixture dropwise for $30 \mathrm{~min}$ and the colorless solution turned white. Afterwards, F127 (0.3 g), resorcinol (1.2 mmol) and formaldehyde solution $(0.56 \mathrm{~mL})$ were dissolved into the above white solution and the resulting solution was stirred for $30 \mathrm{~min}$. The melamine $(4.8 \mathrm{mmol})$ and formaldehyde solution $(0.42 \mathrm{~mL})$ were injected and stirred for $24 \mathrm{~h}$ at $30^{\circ} \mathrm{C}$. After that, a brown solution was obtained and was transferred to a Teflon-lined stainless-steel autoclave, and heated at $100{ }^{\circ} \mathrm{C}$ for $24 \mathrm{~h}$. Eventually, the as-obtained precipitate was separated by centrifugation and washed with deionized water and ethanol several times, and dried at $60{ }^{\circ} \mathrm{C}$ under vacuum for overnight. The resulting sample was labelled $\mathrm{SiO}_{2} @ \mathrm{MRF}$.

\subsection{Preparation of N/C and ND/C}

$\mathrm{SiO}_{2} @ \mathrm{MRF}$ was pyrolyzed under $\mathrm{N}_{2}$ atmosphere in a tube furnace at $700^{\circ} \mathrm{C}$ for $3 \mathrm{~h}$ with a heating rate of $2{ }^{\circ} \mathrm{C} \cdot \mathrm{min}^{-1}$ to yield $\mathrm{SiO}_{2} @ \mathrm{~N} / \mathrm{C} . \mathrm{SiO}_{2} @ \mathrm{~N} / \mathrm{C}$ was then etched by HF (10 wt.\%) for $24 \mathrm{~h}$ at room temperature to remove $\mathrm{SiO}_{2}$ template, filtered and dried at $60{ }^{\circ} \mathrm{C}$ under vacuum, the obtained sample was labeled N/C. N/C as annealed at $1,050^{\circ} \mathrm{C}$ for $2 \mathrm{~h}$ with a heating rate of $5{ }^{\circ} \mathrm{C} \cdot \mathrm{min}^{-1}$ under an atmosphere of nitrogen in order to form defective nitrogen. The resulting sample was denoted as $\mathrm{ND} / \mathrm{C}$.

\subsection{Preparation of Fe-N/C and Fe-ND/C}

The Fe atoms were introduced into the N/C or ND/C via impregnation and heat-treatment followed by acid washing. $\mathrm{N} / \mathrm{C}$ or $\mathrm{ND} / \mathrm{C}(30 \mathrm{mg}), \mathrm{Fe}(\mathrm{acac})_{3}(12.36 \mathrm{mg})$ were dissolved into DMF $(60 \mathrm{~mL})$ by sonication for $1 \mathrm{~h}$. Subsequently, the mixed dispersion solution was heated for $5 \mathrm{~h}$ at $80^{\circ} \mathrm{C}$ in an oil bath under constant stirring conditions and then was treated by the vacuum rotary evaporation method. The obtained black powder was pyrolyzed at $700{ }^{\circ} \mathrm{C}$ for $2 \mathrm{~h}$ with a heating rate of $5{ }^{\circ} \mathrm{C} \cdot \mathrm{min}^{-1}$ under a nitrogen flow in order to stabilize $\mathrm{Fe}$ nanoparticles on the supports. Finally, the obtained solid was treated by the way of acid washing with $0.1 \mathrm{M} \mathrm{HCl}$ for $5 \mathrm{~h}$ at $80{ }^{\circ} \mathrm{C}$ accompanied by stirring and vacuum filtration, followed by drying at $60{ }^{\circ} \mathrm{C}$ in a vacuum oven overnight. The catalysts were denoted as $\mathrm{Fe}-\mathrm{N} / \mathrm{C}$ and $\mathrm{Fe}-\mathrm{ND} / \mathrm{C}$, respectively.

\subsection{Preparation of Fe-ND/C- $x$}

Fe-ND/C was firstly pyrolyzed by heating up at a ramp rate of $5{ }^{\circ} \mathrm{C} \cdot \mathrm{min}^{-1}$ to the temperature of 900 or $1,100{ }^{\circ} \mathrm{C}$ for $2 \mathrm{~h}$ under $\mathrm{N}_{2}$ and then washed by $0.1 \mathrm{M} \mathrm{HCl}$. The obtained samples were named as Fe-ND/C- $x\left(x=900,1,100^{\circ} \mathrm{C}\right)$.

\subsection{Material characterization}

The scanning electron microscopy (SEM) was detected on FEI Quanta 200F scanning electron microscope operating with a point resolution of $2 \mathrm{~nm}$ at $20 \mathrm{kV}$. The transmission electron microscopy (TEM) was acquired using a HITACHI HT7700 at an acceleration voltage of $100 \mathrm{kV}$. High resolution transmission electron microscopy (HRTEM) images were recorded on a JEM-F200 microscope. The aberration corrected high-angle annular dark-field scanning transmission electron microscope (AC-HAADF-STEM) images were performed on JEM-2100 at an acceleration voltage of $200 \mathrm{kV}$. The powder X-ray diffraction (XRD) data was undertaken on a Rigaku D/Max2500PC diffractometer with $\mathrm{Cu} \mathrm{K} \alpha$ radiation $(\lambda=1.5418 \AA)$ over the $2 \theta$ range of $5^{\circ}-80^{\circ}$ with a scan speed of $5 \%$ min at room temperature. X-ray photoelectron spectroscopy (XPS) measurements were performed on an Thermofisher ESCALAB250Xi spectrometer using a monochromated $\mathrm{Al} \mathrm{K} \alpha \mathrm{X}$-ray source $(h v=$ $1,486.6 \mathrm{eV})$. All binding energies were referenced to $\mathrm{C} 1 \mathrm{~s}$ peak $(284.6 \mathrm{eV})$. Raman measurements were obtained by Renishaw inVia Raman microscope with a $532 \mathrm{~nm}$ excitation laser. The elemental analysis of $\mathrm{O}, \mathrm{N}, \mathrm{H}$ were tested on Horiba EMGA930. The Fe loading was determined using inductively coupled plasma optical emission spectrometry (ICP-OES) on ICPS-8100. $\mathrm{N}_{2}$ adsorption-desorption isotherms were performed to determine surface areas and pore volumes with a Micromeritics ASAP 2460 apparatus. The X-ray absorption fine structure spectra Fe K-edge were collected at 1W1B beamline of Beijing Synchrotron Radiation Facility (BSRF). The data were collected in fluorescence mode using a Lytle detector while the corresponding reference sample were collected in transmission mode. The samples were ground and uniformly daubed on the special adhesive tape.

\subsection{Electrochemical measurement}

The electrochemical performance of $\mathrm{Fe}-\mathrm{N} / \mathrm{C}$ catalyst was 
measured on the RARSTAT 3000A-DX Bipotentiostat in a three-electrode electrochemical cell, including a rotating ring-disk electrode (RRDE), a platinum wire and $\mathrm{Ag} / \mathrm{AgCl}$ as the working electrode, counter electrode and reference electrode, respectively. The catalyst ink was prepared by dispersing $5 \mathrm{mg}$ of catalyst powder into mixed solution containing $175 \mu \mathrm{L}$ of ethanol and $47.5 \mu \mathrm{L}$ of 5 wt.\% Nafion solution, followed by sonication for at least $30 \mathrm{~min}$. Then $7 \mu \mathrm{L}$ of the homogeneous ink was dropped on the polished glassy carbon (GC) electrode (5.3 $\mathrm{mm}$ in diameter) with a Pt ring (catalyst loading: $0.71 \mathrm{mg} \cdot \mathrm{cm}^{-2}$ ) and dried at the room temperature.

Before testing, $126 \mathrm{~mL}$ of $0.1 \mathrm{M} \mathrm{KOH}$ solution as the electrolyte in the cell was bubbled with $\mathrm{O}_{2}$ and $\mathrm{N}_{2}$ alternately for at least $30 \mathrm{~min}$ during the measurement. The cyclic voltammetry (CV) and linear sweep voltammetry (LSV) tests were performed at a scanned rate of $10 \mathrm{mV} \cdot \mathrm{s}^{-1}$ in $\mathrm{O}_{2}$-saturated and $\mathrm{N}_{2}$-saturated $0.1 \mathrm{M} \mathrm{KOH}$ solution under the scan potential ranged from 0.1 to $-0.9 \mathrm{~V}$, and the ring electrode potential was set to $1.3 \mathrm{~V}$ vs. RHE. LSV measurements were made at different rotation speed from 400 to $2,025 \mathrm{rpm}$. The corresponding Koutecky-Levich (K-L) plots were chosen at 0.2, 0.3, 0.4, $0.5,0.6 \mathrm{~V}$ in order to fit the electron transfer number $(n)$ from Koutecky-Levich equation

$$
\begin{aligned}
& \frac{1}{J}=\frac{1}{J_{\mathrm{L}}}+\frac{1}{J_{\mathrm{K}}}=\frac{1}{B \omega^{\frac{1}{2}}}+\frac{1}{J_{\mathrm{K}}} \\
& B=0.62 n F C_{0} D_{0}{ }^{\frac{2}{3}} V^{-\frac{1}{6}}
\end{aligned}
$$

where $J$ is the current density, $J_{\mathrm{K}}$ and $J_{\mathrm{L}}$ are the kinetic and limiting current densities, $\infty$ is the angular velocity of the disk, $n$ is the electron transfer number, $F$ is the Faraday constant $\left(96,485 \mathrm{C} \cdot \mathrm{mol}^{-1}\right), \mathrm{C}_{0}$ is the bulk concentration of $\mathrm{O}_{2}(1.2 \times$ $\left.10^{-6} \mathrm{~mol} \cdot \mathrm{cm}^{-3}\right), D_{0}$ is the diffusion coefficient of $\mathrm{O}_{2}$ in $0.1 \mathrm{M}$ $\mathrm{KOH}\left(1.9 \times 10^{-5} \mathrm{~cm}^{2} \cdot \mathrm{s}^{-1}\right)$, and $V$ is the kinematic viscosity of the electrolyte $\left(0.01 \mathrm{~cm}^{2} \cdot \mathrm{s}^{-1}\right)$. The constant 0.62 is adopted when the rotating speed is expressed in $\mathrm{rad} \cdot \mathrm{s}^{-1}$.

Electron transfer number $(n)$ can be determined by another equation, which follows hydrogen peroxide yield $\left(\mathrm{H}_{2} \mathrm{O}_{2} \%\right)$

$$
\begin{aligned}
& \mathrm{H}_{2} \mathrm{O}_{2}(\%)=200 \times \frac{\frac{I_{\mathrm{r}}}{N}}{I_{\mathrm{d}}+\frac{I_{\mathrm{r}}}{N}} \\
& n=4 \times \frac{I_{\mathrm{d}}}{I_{\mathrm{d}}+\frac{I_{\mathrm{r}}}{N}}
\end{aligned}
$$

where $I_{\mathrm{d}}$ is the disk current, $I_{\mathrm{r}}$ is the ring current, and $N$ is the current collection efficiency of the Pt ring $(N=0.37)$.

\section{Results and discussion}

Nitrogen doped hollow carbon spheres with core@shell structure $\left(\mathrm{SiO}_{2} @ \mathrm{~N} / \mathrm{C}\right)$ were prepared by the carbonization of $\mathrm{SiO}_{2} @ M R F$, which was synthesized by a one-pot reaction using a modified Stöber approach by coating $\mathrm{SiO}_{2}$ with melamine(M)resorcinol(R)-formaldehyde(F) polymer. In addition, triblock copolymer Pluronic F127 in the experiment was acted as microstructural template. Finally, the $\mathrm{SiO}_{2}$ core was etched with hydrofluoric acid and the obtained material was denoted as N/C. Nitrogen/defect doped hollow carbon spheres (ND/C) were generated by annealing $\mathrm{N} / \mathrm{C}$ at $1,050{ }^{\circ} \mathrm{C}$ to remove partial nitrogen from $\mathrm{N} / \mathrm{C}$ in order to form nitrogen vacancies. Subsequently, Fe species modified N/C or ND/C (Fe-N/C or $\mathrm{Fe}-\mathrm{ND} / \mathrm{C})$ were obtained via impregnation with $\mathrm{Fe}(\mathrm{acac})_{3}$ dissolved in DMF solution, followed by heat-treatment in $\mathrm{N}_{2}$ atmosphere and acid washing (Scheme 1). SEM and TEM images reveal that $\mathrm{SiO}_{2} @ M R F$ (Fig. S1(a) in the Electronic Supplementary Material (ESM)) and $\mathrm{SiO}_{2} @ \mathrm{~N} / \mathrm{C}$ (Figs. S1(b) and S1(c) in the ESM) exhibit a core@shell structure with shell thickness of $7 \mathrm{~nm}$. After etching by hydrofluoric acid, a uniform hollow spherical structure was formed on N/C (Fig. S1(d) in the ESM) and ND/C (Fig. S1(e) in the ESM), manifesting their excellent structural robustness during the process of etching $\mathrm{SiO}_{2}$ and removing heteroatoms. After inducing $\mathrm{Fe}$ species, $\mathrm{Fe}-\mathrm{N} / \mathrm{C}$ and $\mathrm{Fe}-\mathrm{ND} / \mathrm{C}$ remain the hollow spherical structure (Fig. S1(f) in the ESM and Figs. 1(a) and 1(b)). In addition, the thicknesses of shell are roughly $7 \mathrm{~nm}$ for Fe-ND/C, similar to the thicknesses of shell of ND/C. There are no visible nanoparticles or clusters formed according to AC-HAADFSTEM with subangstrom resolution (Fig. 1(c)), and atomic-scaled dots have been observed on the carbon sphere, revealing the existence of $\mathrm{Fe}$ single atoms on ND/C. Moreover, C, N and Fe mapping images of Fe-ND/C (Fig. 1(d)) characterized by HRTEM reveal that $\mathrm{Fe}$ and $\mathrm{N}$ atoms are uniformly distributed on the prepared hollow carbon spheres. As shown by the powder XRD patterns in Fig. S2 in the ESM, Fe-N/C and Fe-ND/C display only two broad peaks at $24^{\circ}$ and $43^{\circ}$, corresponding to the (002) and (100) planes of graphitic carbon [28]. It is confirmed that no diffraction peaks assigned to Fe nanoparticles was observed in the XRD patterns, which is consistent with the results of AC-HAADF-STEM and TEM images.

The further investigation of the surface chemical composition and valence state of $\mathrm{Fe}-\mathrm{N} / \mathrm{C}$ and $\mathrm{Fe}-\mathrm{ND} / \mathrm{C}$ was

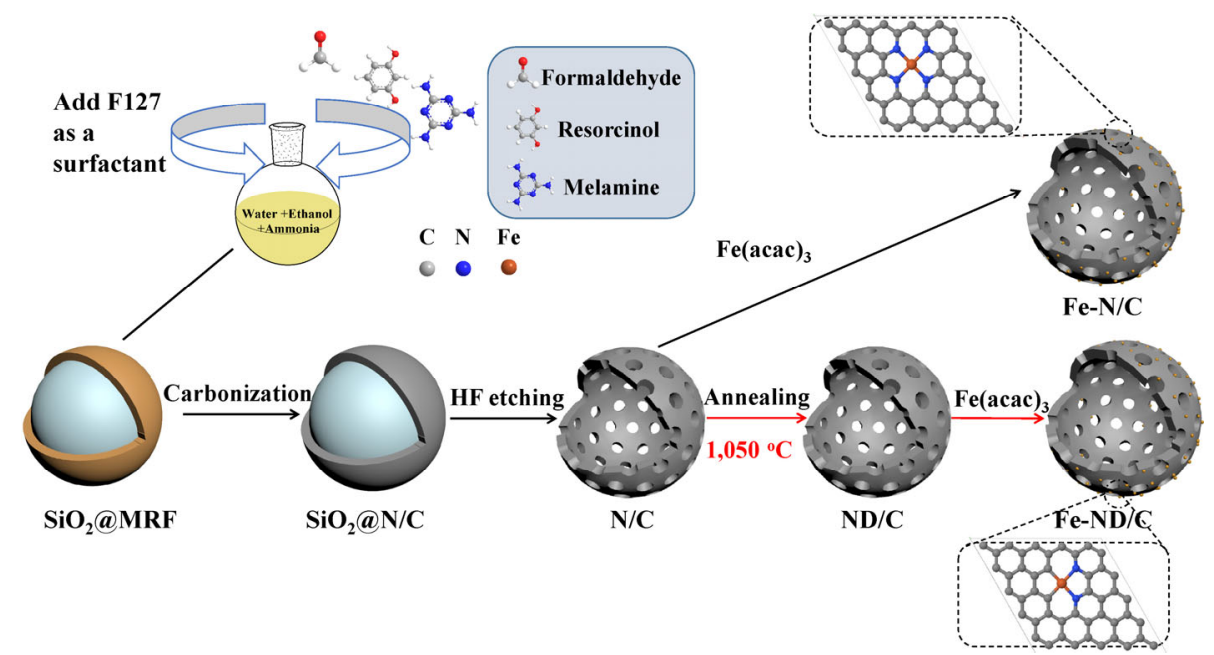

Scheme 1 Schematic illustration for the synthesis process of a pair of electrocatalysts, denoted as Fe-N/C and Fe-ND/C. 

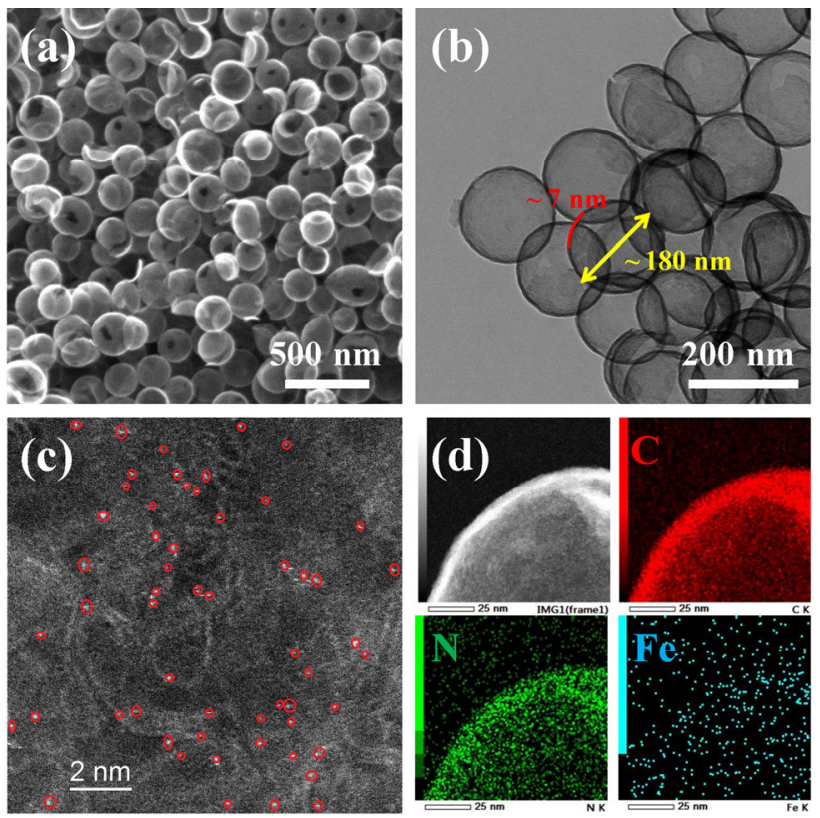

Figure 1 Morphological and structural characterization of the synthesized Fe-ND/C electrocatalysts. (a) SEM, (b) TEM, (c) AC-HAADF-STEM images. The Fe single atoms are marked with red circles. (d) HAADF-STEM image and corresponding EDX element mappings: C (red), N (green), Fe (blue).

measured by XPS. The nature of the surface nitrogen species was analyzed and the result is shown in Fig. 2(a). The N 1s XPS spectra of $\mathrm{Fe}-\mathrm{N} / \mathrm{C}$ and $\mathrm{Fe}-\mathrm{ND} / \mathrm{C}$ can be fitted into three states at $401.2,400.2$, and $398.3 \mathrm{eV}$, which is ascribed to graphitic- $\mathrm{N}$, pyrrolic-N and pyridinic-N, respectively [29]. The three nitrogen species provide different electronic environment for contiguous carbon atoms, resulting in different electrocatalytic activity [20]. The intensity of $\mathrm{N}$ 1s peak for Fe-N/C catalyst decreased obviously after annealing at $1,050{ }^{\circ} \mathrm{C}$. This observation can be verified by the elemental analysis (Table S1 in the ESM). Furthermore, high temperature calcination has great impact on nitrogen species. It should be noted that for $\mathrm{Fe}-\mathrm{ND} / \mathrm{C}$ the nitrogen species were mainly consisted of graphitic and pyridinic- $\mathrm{N}$, which are considered to serve as anchoring sites of $\mathrm{Fe}$ atoms. The relative content of graphitic-N for Fe-ND/C is higher than $\mathrm{Fe}-\mathrm{N} / \mathrm{C}$, while the content of pyrrolic- $\mathrm{N}$ is extremely less than $\mathrm{Fe}-\mathrm{N} / \mathrm{C}$ and pyridinic-N has no obvious decrease, suggesting most of the defect sites are generated from the evaporation of relatively unstable pyrrolic- $\mathrm{N}$ [30]. As shown in Fig. 2(b), the absolute content of graphitic-N remains unchanged.

The degree of defects and graphitization of carbon catalysts were investigated by Raman spectroscopy. Raman spectra clearly exhibit the variation of the intensity of $\mathrm{D}$ and $\mathrm{G}$ bands at 1,350 and $1,590 \mathrm{~cm}^{-1}$ [31], respectively, both for Fe-N/C and Fe-ND/C (Fig. 2(c)). D band represents the defects and disorders of carbon. $\mathrm{G}$ band is attributed to graphitic carbon. Thus, the intensity ratio of $\mathrm{D}$ band and $\mathrm{G}$ band $\left(I_{\mathrm{D}} / I_{\mathrm{G}}\right)$ could be a criterion for the degree of defect. The formation of nitrogen vacancies can enhance the degree of catalyst defect. The $I_{\mathrm{D}} / I_{\mathrm{G}}$ value of $\mathrm{Fe}-\mathrm{ND} / \mathrm{C}(0.97)$ is much higher than Fe-N/C (0.85), indicating the formation of defects on $\mathrm{Fe}-\mathrm{ND} / \mathrm{C}$, which coincides well with the results of XPS spectra.

The Fe loadings of samples were determined by ICP-OES. For $\mathrm{Fe}-\mathrm{ND} / \mathrm{C}$ and Fe-N/C catalysts, Fe content is 0.12 and 0.27 (wt.\%), respectively. Because of the very low Fe content, the Fe $2 \mathrm{p}$ signal of Fe-ND/C and Fe-N/C is very weak (Fig. 2(d)). The binding energies of $\mathrm{Fe} 2 \mathrm{p}$ peak for $\mathrm{Fe}-\mathrm{ND} / \mathrm{C}$ and $\mathrm{Fe}-\mathrm{N} / \mathrm{C}$ are around $711.2 \mathrm{eV}\left(\mathrm{Fe} 2 \mathrm{p}_{3 / 2}\right)$ and $724.5 \mathrm{eV}\left(\mathrm{Fe} \mathrm{2} \mathrm{p}_{1 / 2}\right)$ [32], respectively, indicating the presence of $\mathrm{Fe}^{3+}$ species. The $\mathrm{Fe}^{3+}$ species should be coordinated by vacancy sites and nitrogen species. Fe content of Fe-ND/C rich of vacancy sites is $~ 50 \%$ lower than that of Fe-N/C (Table S1 in the ESM), which may be contributed to the lower coordination interaction of defect sites with $\mathrm{Fe}$ ions (Fe-D) than that of nitrogen species with $\mathrm{Fe}$ ions $(\mathrm{Fe}-\mathrm{N})$.

The valance state and coordination environment of the iron in $\mathrm{Fe}-\mathrm{ND} / \mathrm{C}$ were further characterized using X-ray absorption fine structure (XAFS). Figure 2(e) shows the Fe-K X-ray absorption near-edge structure (XANES) spectra for Fe-ND/C and the reference samples. The XANES absorption edge corresponding to $1 \mathrm{~s}$ to $4 \mathrm{p}$ transitions for $\mathrm{Fe}-\mathrm{ND} / \mathrm{C}$ was located at $7,110 \mathrm{eV}$, which is the same with that for $\mathrm{Fe}(\mathrm{III})$-phthalocyanine. This result indicated that the Fe (III) valence state was dominant in Fe-ND/C, which is consistent with XPS results. The coordination environment of the iron was analyzed by extended X-ray absorption fine structure (EXAFS) in radial distance $\chi(R)$ spectra (Fig. 2(f)), Fe-ND/C exhibits one notable
(1)

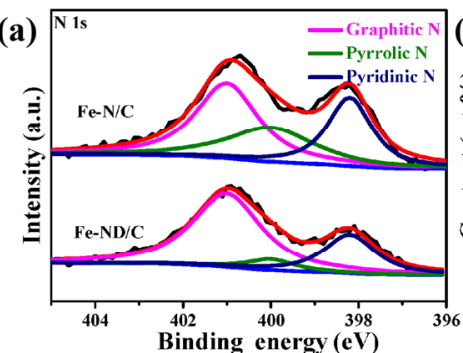

(d)

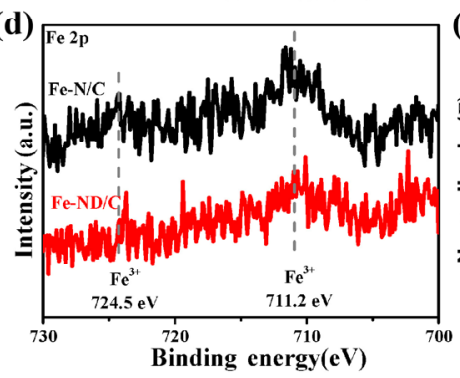

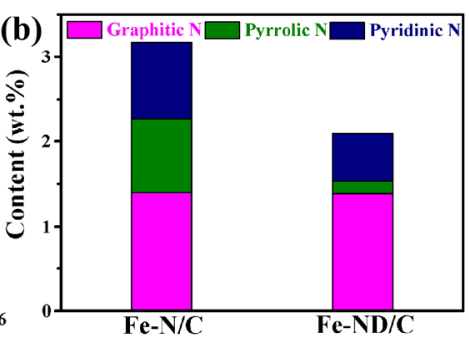

(e)

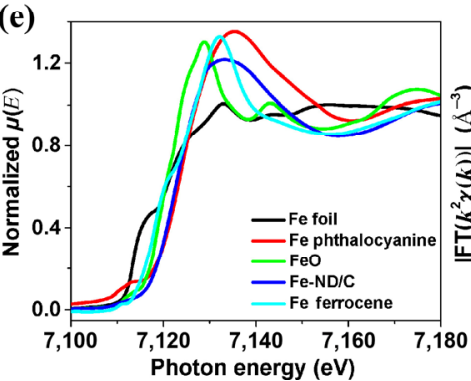

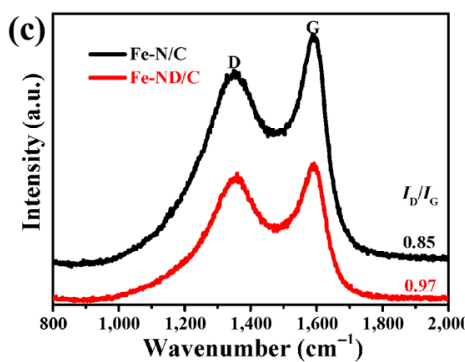

(f)

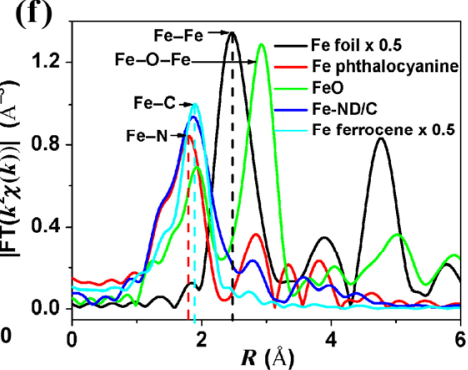

Figure 2 (a) High resolution XPS spectra of N 1s, (b) mass content of N species, (c) Raman spectrum, (d) Fe 2p XPS spectrum for Fe-N/C and Fe-ND/C catalysts, (e) The normalized XANES $\mu(E)$ spectra and (f) The $\mathrm{k}_{2}$-weighted Fourier transform of EXAFS in radial distance $\chi(R)$ spectra at the Fe K-edge for Fe foil, Fe phthalocyanine, FeO, Fe-ND/C and Fe ferrocene 
peak at $1.87 \AA$, which is in between that for Fe-C $(1.90 \AA)$ and $\mathrm{Fe}-\mathrm{N}(1.81 \AA)$. Thus, Fe species may be heterozygous coordinated with nitrogen and carbon. Moreover, the absence of Fe-Fe bond $(2.48 \AA)$ and $\mathrm{Fe}-\mathrm{O}-\mathrm{Fe}$ bond $(2.91 \AA)$ indicated the $\mathrm{Fe}$ species exist as atomically dispersed in Fe-ND/C, which is consistent with HRTEM result. EXAFS fitting shows that $\mathrm{Fe}$ atom on $\mathrm{Fe}-\mathrm{ND} / \mathrm{C}$ was coordinated with two carbon and two nitrogen atoms and one $\mathrm{OH}$ group (Fig. S3 and Table S2 in the ESM).

The electrocatalytic performance of the prepared catalysts for ORR was evaluated in $\mathrm{O}_{2}$ or $\mathrm{N}_{2}$-saturated $0.1 \mathrm{M} \mathrm{KOH}$ aqueous electrolyte via CV and LSV at a scan rate of $10 \mathrm{mV} \cdot \mathrm{s}^{-1}$. No redox-peaks was observed on both catalysts in the $\mathrm{N}_{2}$ bubbled electrolyte, an obvious cathodic peak appeared for each CV curve in $\mathrm{O}_{2}$ bubbled electrolyte (Fig. 3(a)), indicating an effective ORR. The fluctuation of the CV curves in $\mathrm{O}_{2}$ bubbled electrolyte is caused by the slow diffusion of oxygen under resting state [33]. The curve of $\mathrm{Fe}-\mathrm{ND} / \mathrm{C}$ shows a cathodic peak for ORR at $0.79 \mathrm{~V}$ vs. RHE which is more positive than that of $\mathrm{Fe}-\mathrm{N} / \mathrm{C}(0.75 \mathrm{~V}$ vs. $\mathrm{RHE})$, indicating the better ORR electrochemical activity than Fe-N/C. The LSV curves (Fig. 3(b)) further demonstrate the catalytic performance of $\mathrm{Fe}-\mathrm{ND} / \mathrm{C}$ at a rotation rate of 1,600 rpm. Impressively, the onset potential and half-wave potential of $\mathrm{Fe}-\mathrm{ND} / \mathrm{C}$ are measured to be 0.91 and $0.79 \mathrm{~V}$ vs. RHE, respectively, which are higher than those of $\mathrm{Fe}-\mathrm{N} / \mathrm{C}(0.88$ and $0.76 \mathrm{~V}$ vs. RHE), revealing higher electrocatalytic activity of Fe-ND/C. The half-wave potential of Fe-ND/C was compared with previously reported Fe-based catalyst and listed in Table S3 in the ESM. Apart from this, the onset potential of $\mathrm{Fe}-\mathrm{N} / \mathrm{C}$ and $\mathrm{Fe}-\mathrm{ND} / \mathrm{C}$ are more positive than those of the corresponding N/C ( 0.84 vs. $\mathrm{RHE})$ and ND/C (0.86 V vs. RHE) shown in the Fig. S4 in the ESM, indicating Fe-N or Fe-ND sites on Fe-N/C and Fe-ND/C are active centers to catalyze ORR. The iron content on $\mathrm{Fe}$ $\mathrm{ND} / \mathrm{C}$ was tuned, while original $\mathrm{Fe}-\mathrm{ND} / \mathrm{C}$ shows the highest ORR activity (Fig. S5 in the ESM), which indicated that the structure not quantity of active site determines ORR activity. Furthermore, at the potential of 0.7 and $0.8 \mathrm{~V}$ vs. RHE (Fig. 3(c)), the current density of $\mathrm{Fe}-\mathrm{ND} / \mathrm{C}$ is higher than that of $\mathrm{Fe}-\mathrm{N} / \mathrm{C}$, signifying that $\mathrm{Fe}-\mathrm{ND}$ sites are more favorable than $\mathrm{Fe}-\mathrm{N}$ sites for the boosted ORR activity, which means the pyrrolic-N evaporation generate new active sites for ORR activity. The high intrinsic ORR activity of Fe-ND/C can be further verified by the smaller Tafel slope of $73.4 \mathrm{mV} \cdot \mathrm{dec}^{-1}$ compared with that of $\mathrm{Fe}-\mathrm{N} / \mathrm{C}\left(88.7 \mathrm{mV} \cdot \mathrm{dec}^{-1}\right)$. In order to further investigate the influence of surface area of synthesized catalysts for ORR activity, $\mathrm{N}_{2}$ adsorption-desorption isotherms were used to analyze the specific surface area and porous structure of $\mathrm{Fe}-\mathrm{N} / \mathrm{C}, \mathrm{Fe}-\mathrm{ND} / \mathrm{C}$ and their corresponding carbon support (N/C and ND/C) (Fig. S6 and Table S4 in the ESM). The type IV isotherms with a distinct hysteresis loop in the $P / P_{0}$ range of $0.4-1.0$ were found for all samples, indicating a micro/meso porous structure and a large specific surface area [34]. The surface area of $\mathrm{Fe}-\mathrm{ND} / \mathrm{C}$ is $387 \mathrm{~m}^{2} \cdot \mathrm{g}^{-1}$, which is similar to that of $\mathrm{Fe}-\mathrm{N} / \mathrm{C}\left(394 \mathrm{~m}^{2} \cdot \mathrm{g}^{-1}\right)$ (Fig. S6 in the ESM). However, the textural properties of Fe-N/C ( $\left.S_{\text {BET: }} 394 \mathrm{~m}^{2} \cdot \mathrm{g}^{-1} ; V_{\text {micro: }} 0.08 \mathrm{~cm}^{3} \cdot \mathrm{g}^{-1}\right)$ and Fe-ND/C ( $\left.S_{\text {вет: }} 387 \mathrm{~m}^{2} \cdot \mathrm{g}^{-1} ; V_{\text {micro }}: 0.04 \mathrm{~cm}^{3} \cdot \mathrm{g}^{-1}\right)$ are inferior to N/C ( $\left.S_{\text {BET: }} 630 \mathrm{~m}^{2} \cdot \mathrm{g}^{-1} ; V_{\text {micro: }} 0.17 \mathrm{~cm}^{3} \cdot \mathrm{g}^{-1}\right)$ and ND/C ( $S_{\text {BET: }}$ $\left.657 \mathrm{~m}^{2} \cdot \mathrm{g}^{-1} ; V_{\text {micro: }} 0.13 \mathrm{~cm}^{3} \cdot \mathrm{g}^{-1}\right)$, respectively, strongly demonstrating that $\mathrm{Fe}$ species which occupied microchannel partially have modified N/C or ND/C with increased graphitic degree [35]. Therefore, combined with the results of textural properties and ORR activity, the change in activity of all catalysts could be attributed to the activity variation of each active center rather than the difference in specific surface area.

The ORR kinetics of Fe-ND/C catalyst could be illustrated by LSV curves at different rotation rates during 400-2,025 rpm (Fig. 4(a)). As the increase of rotation rates, the current densities increase because of the enhanced gas diffusion [36]. The corresponding Koutecky-Levich (K-L) plots $\left(J^{-1}\right.$ vs. $\left.\omega^{-1 / 2}\right)$ for Fe-ND/C (Fig. 4(b)), fitted at various electrode potentials from Fig. 4(a), present good linearity and parallelism, suggesting a first-order reaction involved with dissolved oxygen concentration and a potential-independent electron transfer rate [37]. Based on the slope of K-L plots, the transferred electron number $(n)$ per oxygen molecule in ORR was calculated as 4.2-4.3 between -0.3 to $-0.6 \mathrm{~V}$ via K-L equation, demonstrating a four-electron transfer process over single active site. It also has been confirmed by RRDE measurements. The $n$ value of $\mathrm{Fe}-\mathrm{ND} / \mathrm{C}$ is 3.9-4.0 and the molar ratio of generated $\mathrm{H}_{2} \mathrm{O}_{2}$ to $\mathrm{H}_{2} \mathrm{O}$ is
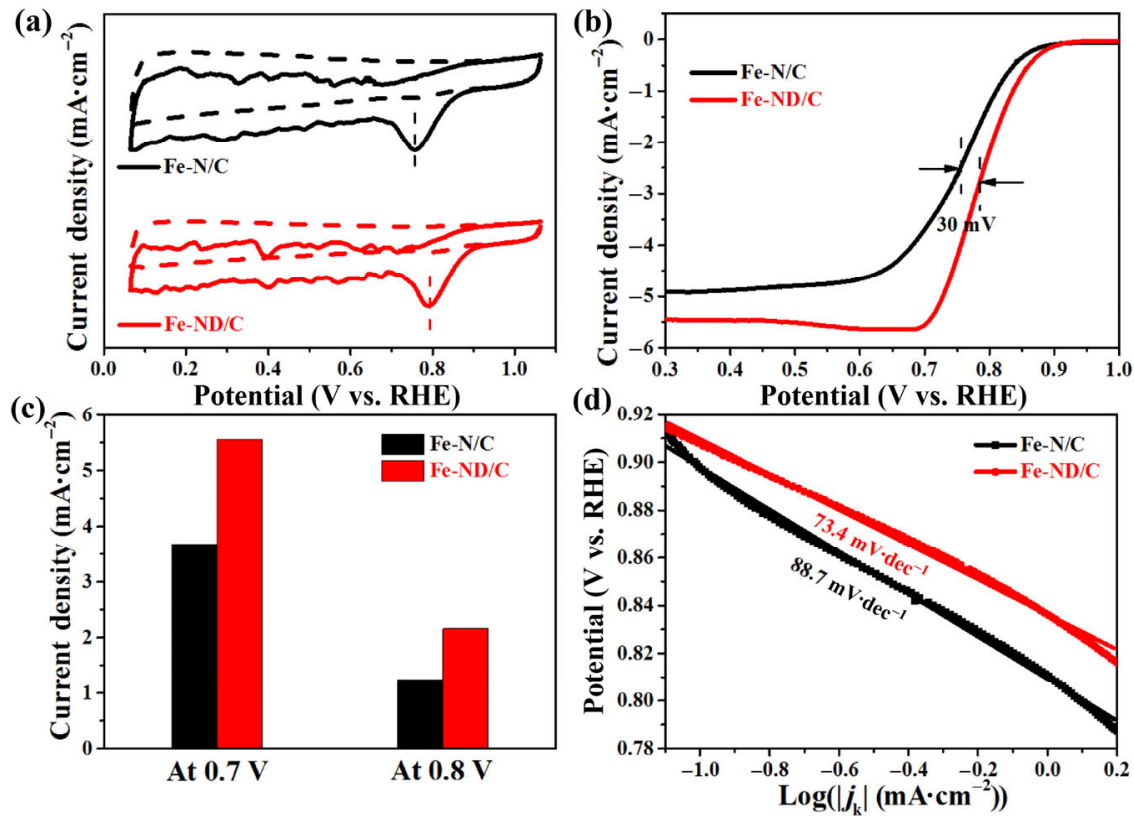

Figure 3 (a) CV curves for the as-prepared samples in $\mathrm{O}_{2}$ (solid line) or $\mathrm{N}_{2}$ (dash line) bubbled $0.1 \mathrm{M} \mathrm{KOH}$ at a scan rate of $10 \mathrm{mV} \cdot \mathrm{s}^{-1}$. (b) LSV curves for Fe-N/C and Fe-ND/C catalysts in $\mathrm{O}_{2}$ bubbled $0.1 \mathrm{M} \mathrm{KOH}$ at a rotation rate of 1,600 rpm with a scan rate of $10 \mathrm{mV} \cdot \mathrm{s}^{-1}$, (c) current density of Fe-N/C and Fe-ND/C catalysts for ORR at 0.7 and $0.8 \mathrm{~V}$ vs. RHE, respectively, and (d) Tafel plots of Fe-N/C and Fe-ND/C. 

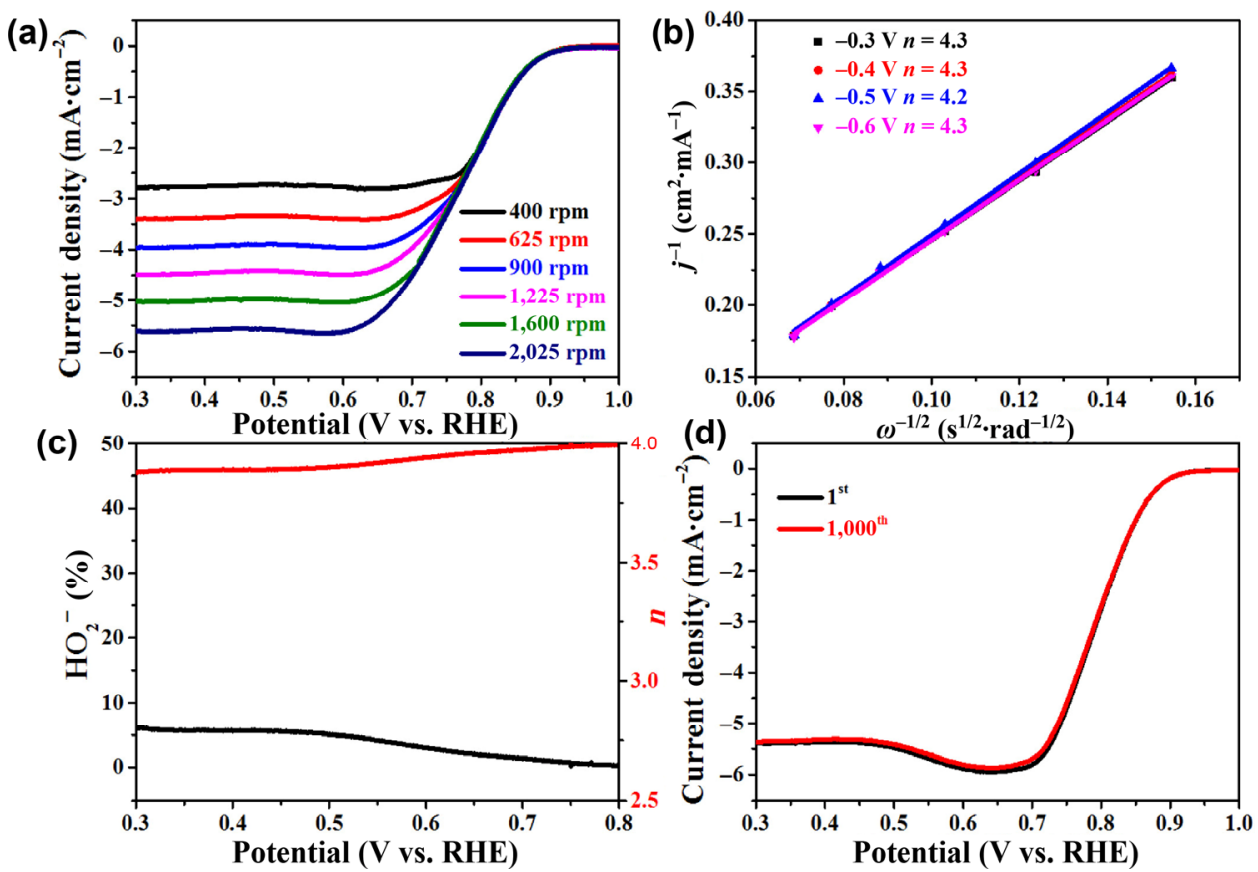

Figure 4 (a) LSV curves of $\mathrm{Fe}-\mathrm{ND} / \mathrm{C}$ catalyst in $\mathrm{O}_{2}$ bubbled $0.1 \mathrm{M} \mathrm{KOH}$ at different rotation rates, (b) $\mathrm{K}-\mathrm{L}$ plots of Fe-ND/C at the potential range of -0.3 to $-0.6 \mathrm{~V}$ vs. RHE, (c) the $\mathrm{H}_{2} \mathrm{O}_{2}$ yield and electron transfer number $(n)$ on per $\mathrm{O}_{2}$ molecular versus potential curve for Fe-ND/C, and (d) $1^{\text {st }}$ and $1,000^{\text {th }}$ LSV curves of Fe-ND/C in $\mathrm{O}_{2}$ bubbled $0.1 \mathrm{M} \mathrm{KOH}$ at 1,600 rpm.

below $6 \%$ within $0.3-0.8 \mathrm{~V}$ (Fig. 4(c)), while $n$ and the $\mathrm{H}_{2} \mathrm{O}_{2}$ yield of Fe-N/C is $3.75-3.95$ and above $10 \%$ within $0.3-0.8 \mathrm{~V}$ (Fig. S7 in the ESM), providing the evidence that the pyrrolic$\mathrm{N}$ evaporation can definitely promote the ORR activity of $\mathrm{Fe}-\mathrm{N} / \mathrm{C}$ by reducing the production of $\mathrm{H}_{2} \mathrm{O}_{2}$. Furthermore, durability is considered as the other key factor to evaluate the property of catalysts in general. The long-term stability of the $\mathrm{Fe}-\mathrm{ND} / \mathrm{C}$ was investigated by LSV after the accelerated durability tests (ADT). A negligible decay in half-wave potential of Fe-ND/C was observed after 1,000 cycles (Fig. 4(d)), revealing a stable LSV performance. In addition, chronoamperometric (CA) tests were performed in $\mathrm{O}_{2}$ bubbled $0.1 \mathrm{M} \mathrm{KOH}$ solution at $0.5 \mathrm{~V}$ vs. RHE to further verify the excellent stability of the Fe-ND/C. Fe-ND/C could maintain $90.7 \%$ of its initial current after running for 18,000 $\mathrm{s}$ (Fig. S8 in the ESM).

To make a deep insight to the influence of defect contents of $\mathrm{Fe}-\mathrm{ND} / \mathrm{C}$ on the ORR activity, Fe-ND/C catalyst was pyrolyzed at different temperatures under a $\mathrm{N}_{2}$ atmosphere followed by acid washing. The resulting samples were denoted as Fe-ND/C- $x(x=$ $\left.900,1,100{ }^{\circ} \mathrm{C}\right)$. ICP result demonstrates that the Fe contents of $\mathrm{Fe}-\mathrm{ND} / \mathrm{C}-x$ are lower than that of Fe-ND/C (0.12 wt.\%), indicating that partial $\mathrm{Fe}$ atoms aggregated into $\mathrm{Fe}$ particle at high temperature and then were leached by acid washing. The similar Fe content ( 0.07 wt.\%) of Fe-ND/C- $x$ suggests that the rest Fe species exist as isolated atoms and show strong thermal stability. As shown in the Table S1 in the ESM, the N content decreases monotonically with the increase of the pyrolysis temperature, demonstrating the number of nitrogen vacancies increases with the increase of temperature. With the similar content of $\mathrm{Fe}$, the catalysts with lower $\mathrm{N}$ content display more excellent ORR activity (Fig. S9 in the ESM). Especially for Fe-ND/C-1,100 with 1.05 wt.\% of $\mathrm{N}$, it shows the highest onset potential (0.94 V vs. RHE) among the tested samples, which is attributed to the presence of more nitrogen defects and the thermally stable Fe single atoms [38]. Therefore, as the increase of the defect contents on Fe-ND/C catalysts, the pyrrolic- $\mathrm{N}$ evaporation generates new active sites for ORR activities.

In order to reveal the origin of the superior ORR activity on
Fe-ND/C than Fe-N/C, first-principles density functional theory (DFT) computations were conducted to address the influence of nitrogen vacancies on the activity for ORR. For a systematic investigation of the ORR performance of Fe-N-C catalyst in an alkaline media, both the active sites of various $\mathrm{Fe}-\mathrm{N} / \mathrm{C}$ anchored with possible reaction intermediates and clean $\mathrm{Fe}-\mathrm{N} / \mathrm{C}$ surfaces have been proposed. The models of $\mathrm{FeN}_{4}, \mathrm{FeN}_{3}$ and $\mathrm{FeN}_{2}$, and corresponding structures anchored with $\mathrm{OH}$ (denoted as $\mathrm{FeN}_{2}-\mathrm{OH}, \mathrm{FeN}_{3}-\mathrm{OH}, \mathrm{FeN}_{4}-\mathrm{OH}$ ) are used for theoretical calculations. Geometric structures of $\mathrm{FeN}_{4}-\mathrm{OH}$, $\mathrm{FeN}_{3}-\mathrm{OH}$ and $\mathrm{FeN}_{2}-\mathrm{OH}$ are shown in Figs. 5(a)-5(c). The ORR process in the alkaline electrolyte, includes the $\mathrm{O}_{2}$ hydrogenation to $\mathrm{OOH}^{\star}, \mathrm{O}-\mathrm{O}$ bond scission of $\mathrm{OOH}^{*}$ to $\mathrm{O}^{*}$, protonation of $\mathrm{O}^{*}$ to $\mathrm{OH}^{*}$, and $\mathrm{OH}^{*}$ removal to form $\mathrm{OH}^{-}$, corresponding free energy diagram are calculated and shown in Fig. 5(d). At $0.455 \mathrm{~V}$ equilibrium potential in alkaline media, all the catalyst models showcase a similar trend of $\mathrm{OOH}^{*} \rightarrow \mathrm{O}^{*}$ reaction step to be exothermic, while other steps are endothermic on three kind of catalyst models. The $\mathrm{OH}^{\star}$ desorption reaction step is found to be the rate-determining step (RDS) and corresponding endothermicity presents the following trend from low to high: $\mathrm{FeN}_{2}-\mathrm{OH}(0.42 \mathrm{eV})<\mathrm{FeN}_{3}-\mathrm{OH}(0.52 \mathrm{eV})<$ $\mathrm{FeN}_{4}-\mathrm{OH}(0.55 \mathrm{eV})$. Compared with $\mathrm{FeN}_{4}-\mathrm{OH}$ catalysts, $\mathrm{FeN}_{2}-$ $\mathrm{OH}$ and $\mathrm{FeN}_{3}-\mathrm{OH}$ models, weaken the strong binding of $\mathrm{OH}^{*}$ intermediate, thereby promoting better desorption of $\mathrm{OH}^{\star}$ binding on the surface. For comparisons, geometric structures of $\mathrm{FeN}_{4}, \mathrm{FeN}_{3}$ and $\mathrm{FeN}_{2}$ are shown in Figs. S10(a)-S10(c) in the ESM, corresponding free energy diagram of the successive steps of formation of $\mathrm{OOH}^{\star}, \mathrm{O}^{\star}, \mathrm{OH}^{\star}$, and desorption of $\mathrm{OH}^{\star}$ are calculated and shown in Fig. S11 in the ESM. The $\mathrm{OH}$ desorption step on $\mathrm{FeN}_{4}, \mathrm{FeN}_{3}$ and $\mathrm{FeN}_{2}$ is still the RDS, as the same with $\mathrm{FeN}_{2}-\mathrm{OH}, \mathrm{FeN}_{3}-\mathrm{OH}, \mathrm{FeN}_{4}-\mathrm{OH}$. The endothermicity presents the following trend from low to high: $\mathrm{FeN}_{4}(0.68 \mathrm{eV})<$ $\mathrm{FeN}_{3}(0.76 \mathrm{eV})<\mathrm{FeN}_{2}(0.92 \mathrm{eV})$, all of these values are much higher than that on catalyst surfaces with $\mathrm{OH}$ ligand. Thus, catalyst with $\mathrm{OH}$ binding maybe as the real active site to catalyze ORR, and the ORR activity of active site $\mathrm{FeN}_{4-x}-\mathrm{OH}$ is higher than $\mathrm{FeN}_{4}-\mathrm{OH}$. For Fe-N/C catalyst, the active site is widely imaged as $\mathrm{FeN}_{4}$. Combing the experimentally superior 

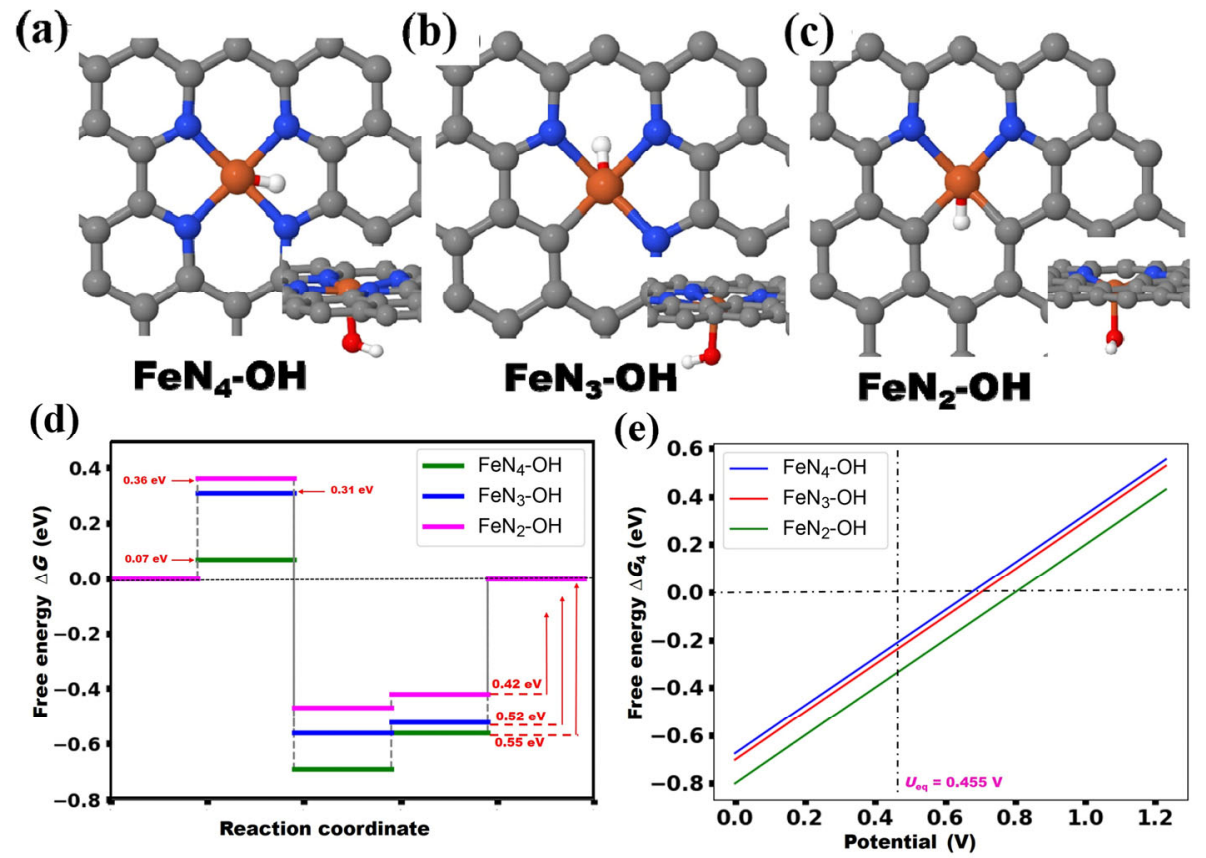

Figure 5 (a)-(c) Front bottom views of $\mathrm{FeN}_{4}, \mathrm{FeN}_{3}, \mathrm{FeN}_{2}$ structures with $\mathrm{OH}$ ligand. The grey, blue, orange, red and white atoms represent $\mathrm{C}, \mathrm{N}, \mathrm{Fe}, \mathrm{O}$ and $\mathrm{H}$ atoms respectively. (d) The free energy profiles of $\mathrm{FeN}_{x}$ with $\mathrm{OH}$ ligand structures for ORR mechanism at $0.455 \mathrm{~V}$ equilibrium potential in alkaline media. (e) Free energy of $\mathrm{OH}^{*} \rightarrow \mathrm{OH}^{-}$as function of electrode potential.

activity of $\mathrm{Fe}-\mathrm{ND} / \mathrm{C}$ than $\mathrm{Fe}-\mathrm{N} / \mathrm{C}$, the active site of $\mathrm{Fe}-\mathrm{ND} / \mathrm{C}$ are proposed as $\mathrm{FeN}_{4-x}$. In order to explore the defect influence for ORR activity, $\mathrm{FeN}_{2}-\mathrm{D}$ with defect sites model was calculated (Fig. $\mathrm{S} 12$ in the ESM). The $\mathrm{OH}$ desorption step on $\mathrm{FeN}_{2}-\mathrm{D}$ is the RDS, as the same with $\mathrm{FeN}_{2}$, and $\mathrm{FeN}_{2}-\mathrm{D}$ presents the lower endothermicity than $\mathrm{FeN}_{2}$. Thus, $\mathrm{FeN}_{2}-\mathrm{D}$ catalyst with defect site shows the high ORR activity than that of $\mathrm{FeN}_{2}$.

Furthermore, to understand the influence of electrode potential on the RDS reaction step for the considered Fe-N-C surfaces, a free energy plot for $\mathrm{OH}^{*} \rightarrow \mathrm{OH}^{-}$reaction step during electrode potential $(0-1.23) \mathrm{V}$ has been drawn in Fig. 5(e). In particular, $\mathrm{OH}^{\star} \rightarrow \mathrm{OH}^{-}$reaction step for $\mathrm{FeN}_{2}-\mathrm{OH}$ becomes exergonic at $\sim 0.8 \mathrm{~V}$ vs. RHE, which essentially consistent with the onset potential toward ORR at Fe-ND-C. In contrast, $\mathrm{OH}^{*} \rightarrow \mathrm{OH}^{-}$reaction step for $\mathrm{FeN}_{4}-\mathrm{OH}$ is still endothermic at $0.8 \mathrm{~V}$. At equilibrium electrode potential $\left(U_{\mathrm{eq}}=0.455 \mathrm{~V}\right)$, the $\mathrm{FeN}_{2}-\mathrm{OH}$ and $\mathrm{FeN}_{3}-\mathrm{OH}$ showcase the much higher exergonic than $\mathrm{FeN}_{4}-\mathrm{OH}$ surface, indicating $\mathrm{FeN}_{2}-\mathrm{OH}$ and $\mathrm{FeN}_{3}-\mathrm{OH}$ presenting higher ORR activity than that of $\mathrm{FeN}_{4}-\mathrm{OH}$. Therefore, it can be concluded that lower Fe-N coordination combined with an $\mathrm{OH}$ ligand $\left(\mathrm{FeN}_{2}-\mathrm{OH}\right)$ showcases the best ORR activity, which corresponds to the experimental result about the superior activity of Fe-ND-C than Fe-N-C. The OH-ligand on catalyst surfaces will behave as active site towards the ORR intermediates and represents a reliable method of ascertaining the performance of catalyst surfaces for ORR.

\section{Conclusions}

In summary, a pair of electrocatalysts, namely, atomic ironnitrogen and iron-nitrogen/defect modified hollow carbon spheres (Fe-N/C and Fe-ND/C) were successfully synthesized by pyrolysis of $\mathrm{Fe}(\mathrm{acac})_{3}$ in the presence of their corresponding hollow carbon spheres. The defect sites are mainly generated via the evaporation of pyrrolic-N on nitrogen doped hollow carbon spheres. The loading amount of atomic iron on $\mathrm{Fe}-$ $\mathrm{ND} / \mathrm{C}$ is $\sim 50 \%$ lower than that of Fe-N/C, indicating coordination interaction of atomic Fe with ND-C is weaker than that with $\mathrm{N}-\mathrm{C}$. Thus, the electronic state of iron affected by coordination environment on Fe-ND/C is different from Fe-N/C, which determine the ORR activity. In alkaline electrolyte, Fe-ND/C shows much higher ORR activity than that of Fe-N/C, revealing that defect sites generated from the pyrrolic- $\mathrm{N}$ evaporation are beneficial for promoting ORR activities. DFT calculations identify that $\mathrm{Fe}-\mathrm{ND} / \mathrm{C}$ catalyst coordinated with $\mathrm{OH}$ ligand is the real active site during ORR process, which weakens the strong binding of $\mathrm{OH}^{*}$ intermediate, thereby promoting better desorption of $\mathrm{OH}^{*}$ binding on the catalyst. Therefore, the ORR activity of Fe-ND-C with nitrogen defect significantly improves compared to that on $\mathrm{Fe}-\mathrm{N}-\mathrm{C}$ without nitrogen vacancies. Thus, comparing to Fe-N sites, Fe-ND sites are more favorable for the enhancement of ORR activity. We believe our findings will provide novel insights for designing electrocatalysts with more pyrrolic- $\mathrm{N}$ vacancies and fundamental understanding of electrocatalytic reactions with atomic clusters catalysts.

\section{Acknowledgements}

This work was supported financially by the National Natural Science Foundation of China (Nos. 21905271 and 21701168), Liaoning Natural Science Foundation (Nos. 20180510029, 20180510043, and 20180510050), the Dalian National Laboratory for Clean Energy (DNL), CAS, DNL Cooperation Fund, CAS (No. DNL180402), and Australian Research Council (No. DP180100568). For XAFS measurement, we gratefully acknowledge 1W1B beamline of Beijing Synchrotron Radiation Facility (BSRF) Beijing, China for providing the beam time.

Electronic Supplementary Material: Supplementary material (TEM imaging, XRD patterns, LSV curves of N/C, DN/C, $\mathrm{H}_{2} \mathrm{O}_{2}$ yield and DFT calculation method) is available in the online version of this article at https://doi.org/10.1007/s12274-0203151-8.

Open Access This article is licensed under a Creative Commons Attribution 4.0 International License, which permits use, sharing, adaptation, distribution and reproduction in any medium or format, as long as you give appropriate credit to 
the original author(s) and the source, provide a link to the Creative Commons licence, and indicate if changes were made.

The images or other third party material in this article are included in the article's Creative Commons licence, unless indicated otherwise in a credit line to the material. If material is not included in the article's Creative Commons licence and your intended use is not permitted by statutory regulation or exceeds the permitted use, you will need to obtain permission directly from the copyright holder.

To view a copy of this licence, visit http://creativecommons.org/licenses/by/4.0/.

\section{References}

[1] Wang, S. Y.; Jiang, S. P. Prospects of fuel cell technologies. Natl. Sci. Rev. 2017, 4, 163-166.

[2] Cheng, Y.; He, S.; Lu, S. F.; Veder, J. P.; Johannessen, B.; Thomsen, L.; Saunders, M.; Becker, T.; De Marco, R.; Li, Q. F. et al. Iron single atoms on graphene as nonprecious metal catalysts for high-temperature polymer electrolyte membrane fuel cells. Adv. Sci. 2019, 6, 1802066.

[3] Kuang, M.; Wang, Q. H.; Han, P.; Zheng, G. F. Cu, Co-embedded $\mathrm{N}$-enriched mesoporous carbon for efficient oxygen reduction and hydrogen evolution reactions. Adv. Energy Mater. 2017, 7, 1700193.

[4] Wang, X. Q.; Li, Z. J.; Qu, Y. T.; Yuan, T. W.; Wang, W. Y.; Wu, Y.; Li, Y. D. Review of metal catalysts for oxygen reduction reaction: From nanoscale engineering to atomic design. Chem 2019, 5, 1486-1511.

[5] Wang, A. Q.; Li, J.; Zhang, T. Heterogeneous single-atom catalysis. Nat. Rev. Chem. 2018, 2, 65-81.

[6] Chen, M. J.; He, Y. H.; Spendelow, J. S.; Wu, G. Atomically dispersed metal catalysts for oxygen reduction. ACS Energy Lett. 2019, 4, $1619-1633$.

[7] Xia, W.; Mahmood, A.; Liang, Z. B.; Zou, R. Q.; Guo, S. J. Earthabundant nanomaterials for oxygen reduction. Angew. Chem., Int. Ed. 2016, 55, 2650-2676.

[8] Xu, Q.; Guo, C. X.; Tian, S. B.; Zhang, J.; Chen, W. X.; Cheong, W. C.; Gu, L.; Zheng, L. R.; Xiao, J. P.; Liu, Q. et al. Coordination structure dominated performance of single-atomic Pt catalyst for anti-Markovnikov hydroboration of alkenes. Sci. China Mater. 2020, 63, 972-981.

[9] Tong, Y. Y.; Guo, H. P.; Liu, D. L.; Yan, X.; Su, P. P.; Liang, J.; Zhou, S.; Liu, J.; Lu, G. Q.; Dou, S. X. Vacancy engineering of irondoped $\mathrm{W}_{18} \mathrm{O}_{49}$ nanoreactors for low-barrier electrochemical nitrogen reduction. Angew. Chem., Int. Ed. 2020, 59, 7356-7361.

[10] Pan, Y.; Lin, R.; Chen, Y. J.; Liu, S. J.; Zhu, W.; Cao, X.; Chen, W. X.; Wu, K. L.; Cheong, W. C.; Wang, Y. et al. Design of single-atom Co- $\mathrm{N}_{5}$ catalytic site: A robust electrocatalyst for $\mathrm{CO}_{2}$ reduction with nearly $100 \%$ CO selectivity and remarkable stability. J. Am. Chem. Soc. 2018, 140, 4218-4221.

[11] Sun, T. T.; Zhao, S.; Chen, W. X.; Zhai, D.; Dong, J. C.; Wang, Y.; Zhang, S. L.; Han, A. J.; Gu, L.; Yu, R. et al. Single-atomic cobalt sites embedded in hierarchically ordered porous nitrogen-doped carbon as a superior bifunctional electrocatalyst. Proc. Natl. Acad. Sci. USA 2018, 115, 12692-12697.

[12] Zhang, L. Z.; Fischer, J. M. T. A.; Jia, Y.; Yan, X. C.; Xu, W.; Wang, X. Y.; Chen, J.; Yang, D. J.; Liu, H. W.; Zhuang, L. Z. et al. Coordination of atomic Co-Pt coupling species at carbon defects as active sites for oxygen reduction reaction. J. Am. Chem. Soc. 2018, 140, 10757-10763.

[13] Zhu, C. Z.; Shi, Q. R.; Xu, B. Z.; Fu, S. F.; Wan, G.; Yang, C.; Yao, S. Y.; Song, J. H.; Zhou, H.; Du, D. et al. Hierarchically porous $\mathrm{M}-\mathrm{N}-\mathrm{C}(\mathrm{M}=\mathrm{Co}$ and $\mathrm{Fe})$ single-atom electrocatalysts with robust $\mathrm{MN}_{x}$ active moieties enable enhanced ORR performance. $A d v$. Energy Mater. 2018, 8, 1801956.

[14] Shen, H. J.; Gracia-Espino, E.; Ma, J. Y.; Tang, H. D.; Mamat, X.; Wagberg, T.; Hu, G. Z.; Guo, S. J. Atomically $\mathrm{FeN}_{2}$ moieties dispersed on mesoporous carbon: A new atomic catalyst for efficient oxygen reduction catalysis. Nano Energy 2017, 35, 9-16.
[15] Li, X. Y.; Rong, H. P.; Zhang, J. T.; Wang, D. S.; Li, Y. D. Modulating the local coordination environment of single-atom catalysts for enhanced catalytic performance. Nano Res. 2020, 13, 1842-1855.

[16] Ding, R.; Liu, Y. D.; Rui, Z. Y.; Li, J.; Liu, J. G.; Zou, Z. G. Facile grafting strategy synthesis of single-atom electrocatalyst with enhanced ORR performance. Nano Res. 2020, 13, 1519-1526.

[17] Li, Y. C.; Liu, X. F.; Zheng, L. R.; Shang, J. X.; Wan, X.; Hu, R. M.; Guo, X.; Hong, S.; Shui, J. L. Preparation of Fe-N-C catalysts with $\mathrm{FeN}_{x}(x=1,3,4)$ active sites and comparison of their activities for the oxygen reduction reaction and performances in proton exchange membrane fuel cells. J. Mater. Chem. A 2019, 7, 26147-26153.

[18] Zhang, Y. Q.; Guo, L.; Tao, L.; Lu, Y. B.; Wang, S. Y. Defect-based single-atom electrocatalysts. Small Methods 2019, 3, 1800406.

[19] Xie, C.; Yan, D. F.; Chen, W.; Zou, Y. Q.; Chen, R.; Zang, S. Q.; Wang, Y. Y.; Yao, X. D.; Wang, S. Y. Insight into the design of defect electrocatalysts: From electronic structure to adsorption energy. Mater. Today 2019, 31, 47-68.

[20] Yan, X. C.; Jia, Y.; Yao, X. D. Defects on carbons for electrocatalytic oxygen reduction. Chem. Soc. Rev. 2018, 47, 7628-7658.

[21] Yan, D. F.; Li, Y. X.; Huo, J.; Chen, R.; Dai, L. M.; Wang, S. Y. Defect chemistry of nonprecious-metal electrocatalysts for oxygen reactions. Adv. Mater. 2017, 29, 1606459.

[22] Zhang, L. Z.; Jia, Y.; Gao, G. P.; Yan, X. C.; Chen, N.; Chen, J.; Soo, M. T.; Wood, B.; Yang, D. J.; Du, A. J. et al. Graphene defects trap atomic Ni species for hydrogen and oxygen evolution reactions. Chem 2018, 4, 285-297.

[23] Yan, X. C.; Jia, Y.; Zhang, L. Z.; Soo, M. T.; Yao, X. D. Defective graphene anchored iron-cobalt nanoparticles for efficient electrocatalytic oxygen reduction. Chem. Commun. 2017, 53, 12140-12143.

[24] Zhao, X. J.; Zou, X. Q.; Yan, X. C.; Brown, C. L.; Chen, Z. G.; Zhu, G. S.; Yao, X. D. Defect-driven oxygen reduction reaction (ORR) of carbon without any element doping. Inorg. Chem. Front. 2016, $3,417-421$.

[25] Jia, Y.; Zhang, L. Z.; Du, A. J.; Gao, G. P.; Chen, J.; Yan, X. C.; Brown, C. L.; Yao, X. D. Defect graphene as a trifunctional catalyst for electrochemical reactions. Adv. Mater. 2016, 28, 9532-9538.

[26] Zhao, H. Y.; Sun, C. H.; Jin, Z.; Wang, D. W.; Yan, X. C.; Chen, Z. G.; Zhu, G. S.; Yao, X. D. Carbon for the oxygen reduction reaction: A defect mechanism. J. Mater. Chem. A 2015, 3, 11736-11739.

[27] Yang, Q.; Jia, Y.; Wei, F. F.; Zhuang, L. Z.; Yang, D. J.; Liu, J. Z.; Wang, X.; Lin, S.; Yuan, P.; Yao, X. D. Understanding the activity of Co- $\mathrm{N}_{4-x} \mathrm{C}_{x}$ in atomic metal catalysts for oxygen reduction catalysis. Angew. Chem., Int. Ed. 2020, 59, 6122-6127.

[28] Chen, Y. F.; Li, Z. J.; Zhu, Y. B.; Sun, D. M.; Liu, X. E.; Xu, L.; Tang, Y. W. Atomic Fe dispersed on N-doped carbon hollow nanospheres for high-efficiency Electrocatalytic oxygen reduction. Adv. Mater. 2019, 31, 1806312.

[29] Guo, D. H.; Shibuya, R.; Akiba, C.; Saji, S.; Kondo, T.; Nakamura, J. Active sites of nitrogen-doped carbon materials for oxygen reduction reaction clarified using model catalysts. Science 2016, 351, 361-365.

[30] Zhou, T. S.; Zhou, Y.; Ma, R. G.; Zhou, Z. Z.; Liu, G. H.; Liu, Q.; Zhu, Y. F.; Wang, J. C. Nitrogen-doped hollow mesoporous carbon spheres as a highly active and stable metal-free electrocatalyst for oxygen reduction. Carbon 2017, 114, 177-186.

[31] Zhang, L. J.; Su, Z. X.; Jiang, F. L.; Yang, L. L.; Qian, J. J.; Zhou, Y. F.; Li, W. M.; Hong, M. C. Highly graphitized nitrogen-doped porous carbon nanopolyhedra derived from ZIF-8 nanocrystals as efficient electrocatalysts for oxygen reduction reactions. Nanoscale 2014, 6 , 6590-6602.

[32] Liu, W. G.; Zhang, L. L.; Liu, X.; Liu, X. Y.; Yang, X. F.; Miao, S.; Wang, W. T.; Wang, A. Q.; Zhang, T. Discriminating catalytically active $\mathrm{FeN}_{x}$ species of atomically dispersed $\mathrm{Fe}-\mathrm{N}-\mathrm{C}$ catalyst for selective oxidation of the C-H bond. J. Am. Chem. Soc. 2017, 139, 10790-10798.

[33] Zhou, T. S.; Ma, R. G.; Zhang, T.; Li, Z. C.; Yang, M. H.; Liu, Q.; Zhu, Y. F.; Wang, J. C. Increased activity of nitrogen-doped graphenelike carbon sheets modified by iron doping for oxygen reduction. $J$. Colloid Interfaces Sci. 2019, 536, 42-52.

[34] Yun, J. Y.; Hwang, S. H.; Jang, J. Fabrication of Au@Ag core/shell 
nanoparticles decorated $\mathrm{TiO}_{2}$ hollow structure for efficient lightharvesting in dye-sensitized solar Cells. ACS Appl. Mater. Interfaces 2015, 7, 2055-2063.

[35] Cheng, W. Z.; Yuan, P. F.; Lv, Z. R.; Guo, Y. Y.; Qiao, Y. Y.; Xue, X. Y.; Liu, X.; Bai, W. L.; Wang, K. X.; Xu, Q. et al. Boosting defective carbon by anchoring well-defined atomically dispersed metal- $\mathrm{N}_{4}$ sites for ORR, OER, and Zn-air batteries. App. Catal. B: Environ 2020, 260, 118198 .

[36] Zhu, A. Q.; Tan, P. F.; Qiao, L. L.; Liu, Y.; Ma, Y. J.; Xiong, X.; Pan, J. Multiple active components, synergistically driven cobalt and nitrogen co-doped porous carbon as high-performance oxygen reduction electrocatalyst. Inorg. Chem. Front. 2017, 4, 1748-1756.

[37] Zhu, A. Q.; Qiao, L. L.; Tan, P. F.; Ma, Y. J.; Zeng, W. X.; Dong, R.; Ma, C.; Pan, J. Iron-nitrogen-carbon species for oxygen electroreduction and $\mathrm{Zn}$-air battery: Surface engineering and experimental probe into active sites. App. Catal. B: Environ. 2019, 254, 601-611.

[38] Yao, Y. G.; Huang, Z. N.; Xie, P. F.; Wu, L. P.; Ma, L.; Li, T. Y.; Pang, Z. Q.; Jiao, M. L.; Liang, Z. Q.; Gao, J. L. et al. High temperature shockwave stabilized single atoms. Nat. Nanotechnol. 2019, 14, 851-857. 